\title{
Pode um desejo imenso...
}

\author{
Maria Helena Serôdio
} Pode um desejo imenso....
arder no peito tanto [...]
Luís Vaz de Camões

Não serei, certamente, a primeira (nem a última...) a citar este verso de Camões para falar de outras formas de desejar e buscar a perfeição das coisas...

E se o faço, agora, é para me referir ao "desejo imenso" que levou um grupo de críticos, investigadores e estudiosos de teatro a criar esta revista - a Sinais de cena - no seio da Associação Portuguesa de Críticos de Teatro (APCT) em Junho de 2004.

Sentíamos que a diminuição progressiva do espaço dedicado ao teatro em jornais e revistas não correspondia nem à sua efectiva importância cultural e artística em Portugal, nem ao gosto e à capacidade crítica que crescia no campo universitário e que, ainda nos anos '90, inspirou a criação de um curso de especialização em Estudos de Teatro na Faculdade de Letras da Universidade de Lisboa, em torno de Osório Mateus e de Maria João Brilhante.

Foi, sem dúvida, um momento de viragem na Universidade Portuguesa que, de resto, veio a desenvolverse posteriormente, também em muitas outras universidades do pais, reforçando a exigência de reflexão em torno do teatro, que já se percebia não ser possivel (e muito menos desejável) ser confinada ao estudo da literatura dramática. E surgiu assim também, há 20 anos e de modo pioneiro no nosso pais, o Centro de Estudos de Teatro na Faculdade de Letras da Universidade de Lisboa, iniciando um percurso de intenso trabalho na investigação desse campo, abrindose ao que de mais avançado se fazia em universidades estrangeiras.

Muitos resultados desse imenso labor estão à vista, como é o caso da criação de várias bases de dados de acesso universal e em permanente actualização: CETbase, base de dados online sobre os espectáculos em Portugal (consultável em http://ww3.fl.ul.pt/CETbase/); OPSIS, Base Iconográfica do Teatro em Portugal (consultável em http://opsis.fl.ul.pt/); HTPonline: Documentos para a História do Teatro em Portugal, mais centrada no séc. XVIII (consultável em http://ww3.fl.ul.pt/cethtp/webinterface/default.htm).

A estas actuações dever-se-ão acrescentar as múltiplas edições críticas de textos dos sécs. XVI, XVII e XVIII, várias outras publicações que saíram com a chancela da Imprensa Nacional - Casa da Moeda, e ainda, mais recentemente, em colaboração com a Universidade de Sevilha, a reconstrução virtual de um teatro em Lisboa de finais do séc. XVI e que foi destruído pelo terramoto em 1755: 0 Pátio das Arcas (acessivel em http://www.tmp.letras.ulisboa.pt/cet-teatros-virtuais).
Procurámos, assim, uma "parceria" entre o jornalismo de reflexão (assegurado pelos críticos de teatro reunidos na APCT), os investigadores que integravam o Centro de Estudos de Teatro da FLUL e os muitos artistas que tantas vezes desafiámos a pensar connosco. Foi aí, nesse espaço - de confluência e de mútuo questionamento - que a Sinais de cena germinou, cruzando o gosto com a exigência, o fazer com o saber.

A espessura do tempo, que foi passando, permitiunos interrogar, estudar e avaliar muito do que em teatro - aqui e em vários lugares no mundo - se ia fazendo, escrevendo e analisando. E muitos foram os colegas de outras universidades (do Porto, Minho, Coimbra, Évora e Algarve) que se juntavam a nós nesta vontade de publicar uma revista inteiramente dedicada ao teatro.

Cumprimos sempre, em cada número, dez formas de ver, investigar e avaliar esse campo artístico, reportando cada uma dessas formas a uma determinada secção: (1) o Editorial, que antecipava os conteúdos e as razões que teriam inspirado grande parte desse número; (2) um "Dossiê temático" que oscilava entre o conjunto de declarações que o júri da Associação Portuguesa de Críticos de Teatro fizera a propósito da atribuição anual do Prémio da Crítica (no número de Junho) e o destaque a uma problemática que suscitava uma investigação, como foi a propósito de Cenografia em Portugal, Performatividades, Pós-dramático, Desafios da crítica, Ficções dramatúrgicas e cenográficas, Corpos em palco e práticas cénicas, repercussão da Implantação da República, Relações entre ciência e teatro, Efeitos da censura, entre vários outros temas; (3) uma longa entrevista a um fazedor de teatro ("Na primeira pessoa"); (4) uma secção que mais do que falar de pessoas, iniciativas ou teatros, dedicava cerca de uma dezena das suas páginas a "contar essa história" através de fotografias ("Portefólio"); (5) um apontamento sobre o que a internet oferece de interessante a quem faz teatro e a quem gosta de ler sobre as artes do palco ("Em rede"); (6) uma secção para textos ensaísticos sobre teatro ou invocando uma temática especifica que se desenvolvera num determinado colóquio ou congresso ("Estudos aplicados"); (7) uma secção para reportar o que em teatro se ia fazendo além fronteiras ("Notícias de fora"); (8) uma outra para analisar espectáculos que subiam à cena em Portugal ("Passos em volta"); (9) lugar ainda para a recensão de livros de e sobre teatro ("Leituras", dedicando o n. o de Junho à lista das publicações de e sobre teatro que teriam saído em Portugal no ano anterior; (10) uma secção ("Arquivo solto") com base numa investigação sobre uma realidade teatral portuguesa de há mais tempo, acolhendo, em geral, resumos de excelentes dissertações e teses que 
iam surgindo nas universidades em torno da História do Teatro em Portugal.

Publicámos textos importantes de teóricos e analistas do fenómeno teatral no plano internacional - sempre em traduções cuidadas - como foi o caso de Béatrice PiconVallin, Erika Fischer-Lichte, Patrice Pavis, Aleks Siertz, Georges Banu, Ian Herbert, Marvin Carlson, Jean-Pierre Sarrazac, David Edgar, Didier Plassard, entre muitos outros.

Ao longo destes onze anos vivemos intensamente esta responsabilidade, desenvolvemos competências analíticas, demos conta do que em teatro se ia fazendo, auscultando sensibilidades, predilecções, objectivos e formas de fazer, entender e recensear o que o teatro foi sendo ou provocando: em palco, na escrita, no estudo, no registo iconográfico e documental.

Contámos sempre com a compreensão e ajuda de muitos artistas, fotógrafos, arquivistas, estudiosos de várias especialidades. Nunca Ihes poderemos agradecer suficientemente a sua generosidade.

No entanto, como sempre acontece na vida, estes anos não foram só tempo de celebrar as artes do espectáculo e viver intensamente esse projecto... 0 tempo foi-nos cerceando também a alegria, roubando-nos amigos dedicados, parceiros competentes e generosos, como foi o Carlos Porto (1930-2008), o Luiz Francisco Rebello (19242011) e, ainda mais inesperadamente o Paulo Eduardo Carvalho (1964-2010). Mas foi por eles, também, que fomos continuando esta aventura, prosseguindo os caminhos que eles nos abriram, partilhando o que deles aprendemos, e prolongando os seus ensinamentos, o seu incondicional amor ao teatro.

A Sinais de cena foi sendo esse lugar de trabalho partilhado, encontrando no Centro de Estudos de Teatro da FLUL a sua maior inspiração e apoio. Todavia, e apesar do trabalho de topo que o Centro foi desenvolvendo, a mais recente avaliação internacional dos Centros de investigação penalizou, de forma injusta - incompreensivel, mesmo - sobretudo os que estudam e investigam as artes, incluindo este, pelo que um dos muitos efeitos do estrangulamento orçamental será a inviabilidade do seu contributo fundamental para a publicação desta revista. É este, portanto, o nosso último número, que, mesmo assim, só consegue sair com o apoio pontual - mas generoso - da Fundação D. Luís I, de Cascais. Não podemos, por isso, deixar de agradecer a prontidão com que respondeu ao nosso apelo! Tal como fizeram, ao longo dos anos, os dois Teatros Nacionais - D. Maria II e S. João com a sua inestimável confiança.

Encontramos reunidas - no "Dossiê temático" deste número - as comunicações que foram apresentadas no colóquio "0 feminino no teatro" que, por iniciativa do Centro de Estudos de Teatro, decorreu na FLUL em Março deste ano e de que já demos conta - parcial - no "Portefólio" do número anterior desta revista ao inserirmos a colecção de retratos de actrizes que esteve então exposta na Faculdade, graças à linha de investigação OPSIS. E é ainda uma voz - e importante presença - feminina do Teatro e da Dança, a Madalena Victorino, que escolhemos apresentar "em directo" na secção "Na primeira pessoa" deste número, reservando o "Portefólio" para lembrar um Festival que foi trazendo até nós ritmos e imagens importantes para um teatro que se quis de hoje e decididamente interventivo: o Alkantara Festival.

Enquanto os "Estudos aplicados" nos fazem reflectir sobre o corpo e a dança em torno das comunicações apresentadas no encontro que o CET dinamizou - Corpo presente: Novos discursos sobre o corpo nas artes performativas em Portugal -, as "Notícias de fora" levamnos em breves "viagens" pela Itália e pela Guiné, falando de espectáculos de clara intervenção social e política, enquanto de Paris nos chegam notícias sobre o Festival de Outono.

E é ainda de um outro Festival, mas em Portugal Materiais Diversos -, que se escreve na secção "Passos em volta", cabendo ainda, por esses "passos", uma análise do que o Mundo Perfeito fez no palco do São Luiz Teatro Municipal a partir de Madame Bovary.

Uma visão alargada de peças, que recentemente foram publicadas entre nós, integra a secção "Leituras", na análise minuciosa de Sebastiana Fadda, partilhando o espaço de escrita com a apresentação, por Ana Campos, do livro de Paula Magalhães sobre o Chiado na Belle Époque.

Um outro espaço reportado ao teatro - mas longe do centro lisboeta - ocupa uma outra secção - o "Arquivo solto" -, que Judite Lopes usa para desenhar a geografia teatral da cidade de Aveiro ao longo dos tempos.

Cabe-nos agradecer - em nome do Conselho Redactorial e do Conselho Consultivo desta revista - a todos os que, de forma cúmplice e desinteressada, nos acompanharam neste trajecto, fosse em colaborações pontuais ou de forma mais persistente. E se comecei este Editorial citando um poeta português para falar do "desejo imenso" que inventou esta revista, finalizarei com um outro poeta, T. S. Eliot, que, em 1925, encerra o seu poema The Hollow Men declarando:

É assim que o mundo acaba

É assim que o mundo acaba

É assim que o mundo acaba

Não com um estrondo mas com uma lamúria. 